\title{
Initial Experience with Brain Mapping under Awake Craniotomy for Resection of Insular Gliomas of the Dominant Hemisphere
}

Mohammad Shirani ${ }^{1^{*}}$, Maysam Alimohamadi ${ }^{2}$, Reza Shariat Moharari ${ }^{3}$, Koorosh Karimi Yarandi ${ }^{4}$, Seyed Ebrahim Ketabchi ${ }^{5}$, Abbas Amirjamshidi ${ }^{6}$

\begin{abstract}
${ }^{1}$ MD, Assistant Professor of Neurosurgery, Sina Hospital, Brain and Spinal Cord Injury Research Center, Neuroscience Institute, Tehran University of Medical Sciences, Tehran, Iran

${ }^{2} \mathrm{MD}$, PhD, Assistant Professor of Neurosurgery, Sina Hospital, Department of Neurosurgery, Tehran University of Medical Sciences, Tehran, Iran

${ }^{3}$ MD, Professor of Anesthesiology, Department of Anesthesiology, Sina Hospital, Tehran University of Medical Sciences, Tehran, Iran

${ }^{4}$ MD, Assistant Professor of Neurosurgery, Sina Hospital, Department of Neurosurgery, Tehran University of Medical Sciences, Tehran, Iran

${ }^{5}$ MD, Professor of Neurosurgery, Sina Hospital, Department of Neurosurgery, Tehran University of Medical Sciences, Tehran, Iran

${ }^{6} \mathrm{MD}$, Professor of Neurosurgery, Sina Hospital, Department of Neurosurgery, Tehran University of Medical Sciences, Tehran, Iran

* Corresponding Author Address: Sina Hospital, Department of Neurosurgery, Tehran University of Medical Sciences, Tehran, Iran. Postal Code: 1136746911. Tel: +989126010043. Fax:+982166348553. Email: drmshirani@yahoo.com
\end{abstract}

Article Type: Case Series

Received: June 24, 2016, Last Revised: September 6, 2016, Accepted: September 10, 2016

\section{Abstract}

Background \& Importance: Insular lobe is located at the depth of sylvian fissure and is hidden by frontal, temporal and parietal lobes in close vicinity of internal capsule and basal ganglia and adjacent to the speech centers in the dominant hemisphere. Thus, radical resection of insular gliomas can be even more difficult. Brain mapping techniques can be used to maximize the extent of tumor removal and minimize postoperative morbidities.

Case Presentation: Patients with newly diagnosed gliomas of dominant insula were enrolled. The exclusion criteria were severe cognitive and/or psychological disturbances, those with difficulty in communication, older than 65 years, severely obese patients, those with difficult airways for intubation and severe cardiovascular or respiratory diseases. All patients were evaluated by contrast enhanced brain MRI, functional brain MRI and diffusion tensor tractography of language and motor systems preoperatively. All were operated under awake craniotomy with the same anesthesiology protocol. Intraoperative monitoring included continuous motor evoked potential, electromyography, electrocorticography, direct electrical stimulation of cortex and subcortical tracts. They were followed with serial neurological examination and imaging.

Conclusion: Seven patients were enrolled including 3 man and 4 women with mean age of 44.4 years. 5 patients suffered from low grade and 2 from high grade glioma. The most common clinical presentation was seizure followed by speech disturbance, hemiparesis and memory loss. Extent of tumor resection ranged from 73 to $100 \%$. No mortality or major postoperative neurological deficit was encountered. Seizure control improved in 3/4 of patients with medical refractory epilepsy. One patient suffered from permanent deterioration of speech after surgery.

Brain mapping under awake craniotomy may be considered a safe method to maximize the extent of tumor resection, while preserving neurological function in patients with gliomas of the dominant insular lobe.

Keywords: Insular Glioma; Awake Craniotomy; Brain Mapping; Cortical Stimulation

Please cite this paper as: Shirani M, Alimohamadi M, Shariat Moharari R, Karimi Yarandi K, Ketabchi S.E, Amirjamshidi A. Initial Experience with Brain Mapping under Awake Craniotomy for Resection of Insular Gliomas of the Dominant Hemisphere. Iran. J. Neurosurg. 2016;2(2):10-14

\section{Background and Importance}

Gliomas are the most common primary tumors of brain $(1,2)$. Currently, the optimal management of gliomas is based on maximal safe resection for patients suffering from high or low grade gliomas (3-5). Because of the infiltrative nature of gliomas, it is not always possible to achieve gross total resection (GTR) and preserving the function of the eloquent structures. GTR with a low risk of morbidity i.e. onco-functional balance is considered as the goal of surgery for all these patients (6).

Insular lobe is located at the depth of sylvian fissure and is hidden by frontal, temporal and parietal lobes in close vicinity of internal capsule and basal ganglia and adjacent to the speech centers in the dominant hemisphere (7). Radical resection of insular gliomas can be even more difficult.

Brain mapping techniques can be used to detect the eloquent areas of the brain intraoperatively; so that the extent of tumor removal is maximized and postoperative morbidities are minimized (8-12).

In this article, we presented our preliminary experience with application of intraoperative functional mapping of motor and speech functions for surgical resection of cerebral gliomas.

\section{Case Presentation}

\section{Patient Population}

We have prospectively enrolled patients with gliomas of the dominant insular lobe without prevous surgery and/or chemoradiation. Complete neurological, psychological and neuroradiological evaluations were done preoperatively.

Patients with severe cognitive and/or psychological disturbances, those with difficulty in communication, older than 65 years, severely obese patients, those with difficult airways for intubation and severe cardiovascular or respiratory diseases were excluded from this study. 


\section{Imaging and Neurophysiologic Tests}

The topography of the tumor was assessed on a preoperative MRI (T1-weighted images before and after Gd-enhancement, T2-weighted and FLAIR images in 3 orthogonal planes and volumetric sequences). MR spectroscopy was done for all patients to obtain a multipixel MR spectroscopic map of the tumor. We performed functional MRI (fMRI) for motor and language tasks for all patients, and interpreted fMRI images for hemispheric dominance and surgical planning. DTI tractography of the white matter fiber tracts involved in motor (corticospinal tract) and language functions (Arcuate fasciculus, inferior and superior longitundinal fasciculus, Uncinate fasciculus and inferior frontooccipital fasciculus) was done for all of the patients.

Intaroperatively, direct electrical stimulation (DES) along with electromyography (EMG) and electrocorticography (ECoG) and motor evoked potential (MEP) were performed for neurophysiological monitoring.

We recorded EcoG continuously during the entire duration of surgery using subdural strip electrodes with 4-8 contacts from the cortex near the mapping area to monitor occurrence of electrical seizures and after-discharges during resection. We used EMG electrodes for face and limb muscle groups to detect motor activities. Continuous MEP recording was used in alternation with DES especially with regard to cerebral ischemia while working in the depth of sylvian fissure and around the perforator branches of middle cerebral artery.

Mapping with DES was done using a constant current generator delivering biphasic square wave pulses across $5 \mathrm{~mm}$ spaced bipolar electrodes. Each point was stimulated 2-4 seconds ( 2 for motor and 4 for language areas) and at least 3 times. No point was stimulated two successive times to avoid occurrence of seizure. The intensity of stimulation ranged from 1.5 to $8 \mathrm{~mA}$. We defined speech arrest when number counting was blocked and none of the below findings were present 13:1Subclinical seizure activity, 2- Simultaneous motor activity in the mouth and/or oropharynx, 3- Visible or perceived muscle contraction affecting speech.

Tumor resection was done alternately with subcortical stimulation. We stopped resection when no gross tumor was visible under microscopic observation, or a functional cortical area or fiber tract was encountered.

The extent of tumor resection was estimated by comparing the early postoperative FLAIR images with the preoperative images and was coined by percentile (Table 1).

\section{Findings}

Seven consequent patients diagnosed to have cerebral glioma for the first time were enrolled including 3 men and 4 women with age range of 28-70 years (mean age=44.4). There were 2 cases of high grade and 5 cases of low grade glioma. The most common clinical presentation was seizure (5 patients) which was medically refractory in 4 patients. Other symptoms included mild speech disturbance (each in 3 patients), hemiparesis and memory disturbance (1 patient) (Table 1).

Extent of resection ranged from 73-100\% (mean:86.2\%). There was neither a mortality nor any major new morbidity (neurological deficit) in this series. Two patients experienced intraoperative seizure (one clinically evident and one recorded electrically) successfully managed by irrigation with cold saline. All the patients were presented in the neuro-oncology tumor board of our department to reach a consensus about adjuvant therapies. They were followed regularly with serial clinical examination and neuroimaging. The follow-up period in this study ranged from 8 to 11 months (median 9.5 months). Only one patient with pre-existing speech problem, had worsening of speech that improved after 3 months postoperatively. Among 4 patients with medically refractory epilepsy, 3 had favorable seizure control during follow-up; one of them experienced no seizure during the 7 months postoperative period of follow up. Speech disorder remained unchanged in1, worsened in 1 and became normal in one patient.

\section{Illustrative Case}

A 30-year-old woman presented with temporal lobe epilepsy since 4 months ago that was controlled. She developed mild receptive dysphasia since one week before admission. A contrast enhanced brain MRI (Figure 1) was compatible with a suspected low grade glioma of the left insula. FMRI and DTI fiber tractography (motor and language) were done (Figure 2). During surgery, stimulation of the posteroinferior part of the tumor induced severe conductive aphasia. The tumor was grossly visible in this area under the microscope, but it was left behind due to positive response in multiple attempts of stimulation. Postoperative MRI confirmed gross removal of the tumor except for the postero-inferior part of it (Figure 3).

Postoperatively, the patient had significant deterioration of speech (receptive), but it started to resolve rapidly during the hospital stay. At 3 months of follow-up, her speech comprehension was similar to the preoperative status.

\section{Discussion}

Brain mapping is used with the aim of localization and preservation of functional cortical and subcortical areas during resection of the maximum possible tumor mass. We would like to discuss our results and compare them with the related literature. We will also have a brief review on 1) how mapping helps to achieve better neurological outcome and 2) how much does it affect the extent of tumor excision.

\section{1-Improvement of Neurological Outcome}

Our results show that no new neurological deficit occurred postoperatively and only one patient (10\%) experienced deterioration of previously disturbed language function. This can convey a $90 \%$ precision of technique in this small series of cases in our hands.

Bertani G. et al. reported that permanent motor or speech deficits occurred in $2.3 \%$ of their cases. However, this figure increased to $7 \%$ among patients who had some degree of preoperative neurological impairments (8). They reported a neurological complication rate of $23 \%$ before administration of intraoperative mapping in their institute. Their study included heterogenous cases with tumors at different locations of the brain, and from both dominant and non-dominant hemispheres. Some of their patients were operated under awake craniotomy and some under general anesthesia only.

Duffau et al. reported the largest homogenous group of insular low grade gliomas of the dominant hemisphere (24 patients) which were all operated under awake craniotomy (6). 3 month after surgery, none of their patients suffered from new speech problem, and 6 of 7 patients with preoperative speech disturbance, improved significantly. Seizure control was also satisfactory in $83 \%$ of their cases after operation. The major difference between their study and ours is that our series included both low grade and high grade gliomas. It is known that low grade gliomas usually cause neurological deficit via 
Table 1. Comparing the Early Postoperative FLAIR Images with the Preoperative Images

\begin{tabular}{|c|c|c|c|c|c|c|c|}
\hline No. & Age & Sex & $\begin{array}{l}\text { Clinical } \\
\text { Presentation }\end{array}$ & Histopathology & $\begin{array}{l}\text { Extent of } \\
\text { Resection }\end{array}$ & $\begin{array}{l}\text { Early Postoperative } \\
\text { Neurological Deficit }\end{array}$ & Neurological Outcome (3 Months) \\
\hline 1 & 47 & Male & $\begin{array}{l}\text { Seizure (Medical } \\
\text { Refractory) }\end{array}$ & LGG & $100 \%$ & 3 Episodes of Seizure & $\begin{array}{c}\text { Significant Improvement of Seizure } \\
\text { Control }\end{array}$ \\
\hline 2 & 58 & Male & $\begin{array}{l}\text { Hemiparesis, Speech } \\
\text { Disturbance (Mostly } \\
\text { Expressive) }\end{array}$ & HGG & $92 \%$ & None & $\begin{array}{l}\text { Deteriorated Expressive } \\
\text { Aphasia, Hemiparesis Unchanged }\end{array}$ \\
\hline 3 & 30 & Female & $\begin{array}{l}\text { Seizure, Speech } \\
\text { Disturbance, } \\
\text { (Mostly Wernicke) }\end{array}$ & LGG & $86 \%$ & $\begin{array}{c}\text { Deteriorated Wernicke } \\
\text { Aphasia }\end{array}$ & $\begin{array}{c}\text { Speech Returned to Preoperative } \\
\text { Status }\end{array}$ \\
\hline 4 & 70 & Female & $\begin{array}{l}\text { Seizure (Medical } \\
\text { Refractory) }\end{array}$ & HGG & $90 \%$ & Transient Global Aphasia & No Improvement in Seizure Control \\
\hline 5 & 43 & Male & $\begin{array}{c}\text { Seizure (Medical } \\
\text { Refractory), Memory } \\
\text { Disturbance }\end{array}$ & LGG & $93 \%$ & Mild Dysphasia & $\begin{array}{l}\text { No Seizure Occurred during } \\
\text { Follow-up }\end{array}$ \\
\hline 6 & 28 & Female & $\begin{array}{l}\text { Speech Disturbance } \\
\text { (Conductive) }\end{array}$ & LGG & $88 \%$ & None & Nearly Normal Speech \\
\hline 7 & 35 & Female & $\begin{array}{l}\text { Seizure (Medical } \\
\text { Refractory) }\end{array}$ & LGG & $73 \%$ & None & Improvement in Seizure Control \\
\hline
\end{tabular}
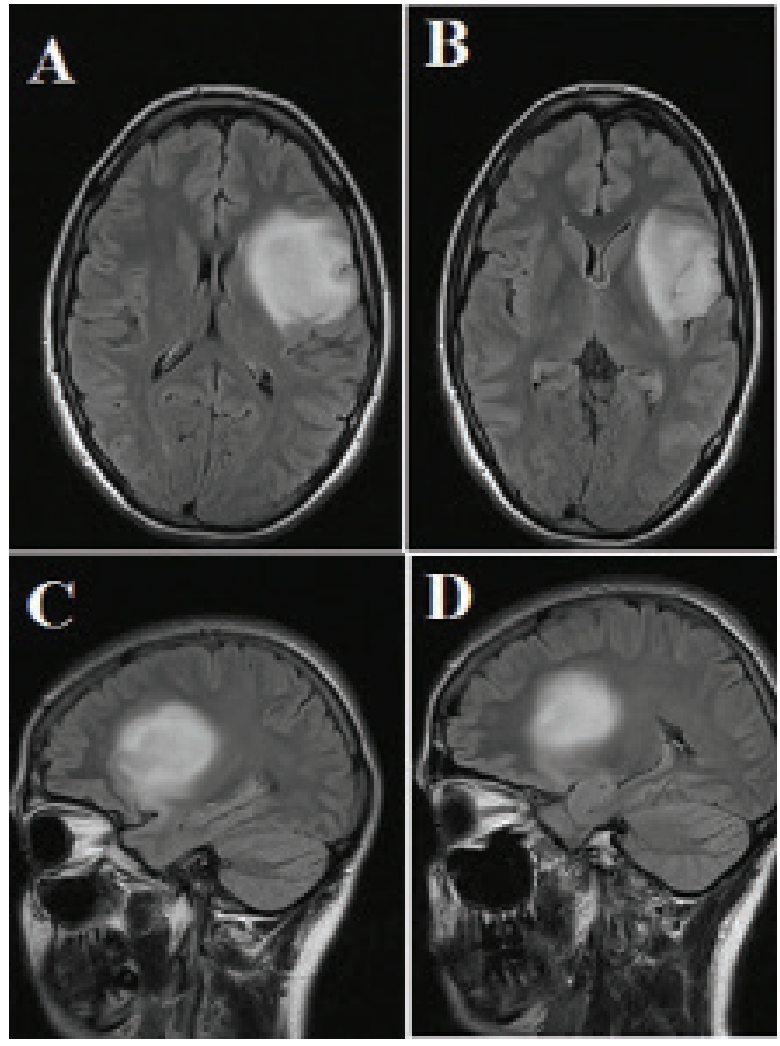

Figure 1. Axial (A\&B) and Sagittal (C\&D) Sections of Preoperative MRI; Showing a Left Insular Tumor with Involvement of the Left Opercular Cortex. Gd-enhanced
MRI Revealed no Contrast Enhancement by the Tumor.

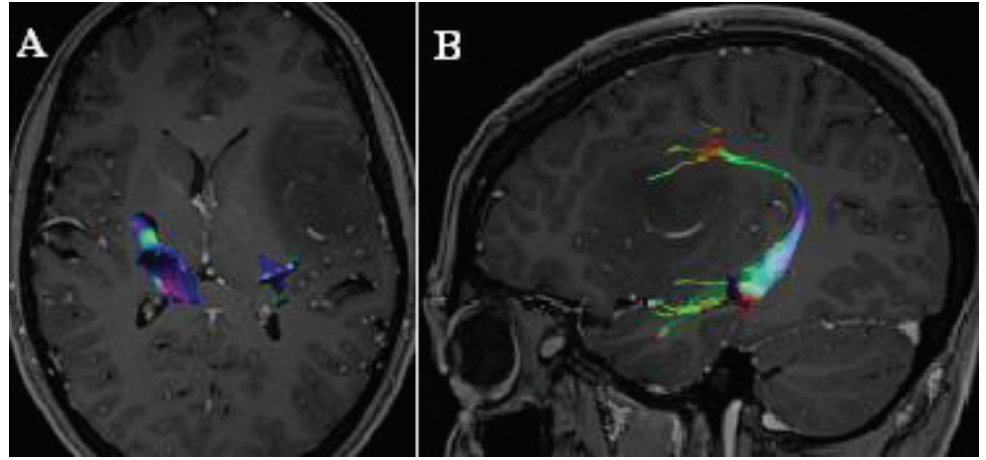

Figure 2. A: Axial DTI-fiber Tractography; Showing a Stretched Corticospinal Tract at the Postero-medial Border of the Tumor. B: Sagittal DTI-fiber Tractography Images Showing Close Proximity of the Postero-inferior Tumor Margin to the Temporal Speech Centre and the Arcuate Fasciculus.

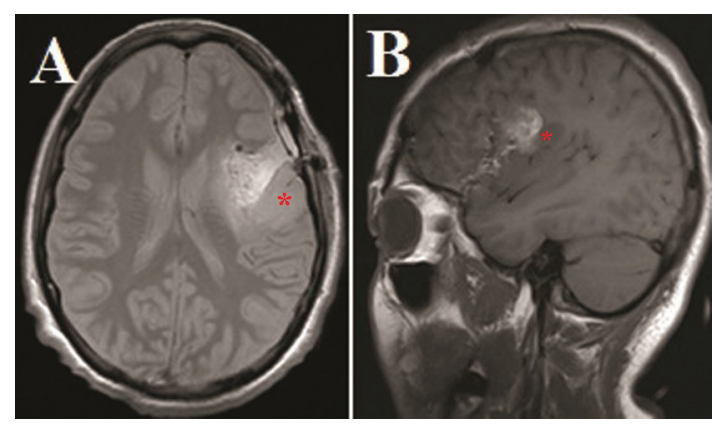

Figure 3. Postoperative Axial Proton Density (A) and Sagittal FLAIR Images; Showing Tumor Residue at the Postero-inferior Border (Red Star). 
compression of the surrounding structures, while the high grade lesionstend toinfiltratetheneighboringbrainregions. Furthermore, progressive tumor growth and application of radiotherapy to the tumor bed may also reduce the chance of recovery of neurological function of the surrounding eloquent areas.

Like the above series, most of the postoperative neurological deficits were temporary in our series, and an interval of 3 months could be considered before judgment about permanency of the deficits.

As long as a $5 \mathrm{~mm}$ margin is preserved between the resection cavity and eloquent regions, permanent neurological deficits seem to be less likely $(8,13)$.

It is said that temporary neurological deficits occur when tumor resection is carried close to subcortical white matter tracts, as a result of fiber tract edema or retraction injury $(6,8)$. Ischemic insult to the corticospinal tract can be best avoided using continuous MEP monitoring which is very sensitive to vascular injuries. This is very crucial when dealing with insular tumors infiltrating between small perforating branches of MCA.

Most of the permanent complications after surgery of insular gliomas reported in the literature are due to vascular insult and stroke $(6,14-20)$. According to Duffau et al. the main language pathways in the dominant hemisphere, run medial to insula but just lateral to the anterior perforated substance which embeds lenticulostriate perforator vessels. Thus, localization of these pathways acts also as a functional barrier to prevent damage to perforating arteries. This may explain lack of vascular injury in our series and the others who have used intraoperative mapping for resection of insular gliomas $(6,8,21)$.

\section{2- Extent of Tumor Removal}

Since first description of insula by Johann C. Reil, it has been considered as a" no man's land" for many years (22). Due to close proximity of insula to motor, language and memory pathways (especially in the dominant hemisphere), insular gliomas were subjected to conservative policies such as "wait and see" or "biopsy and adjuvant therapy" until they grow very large or caused significant neurological morbidity for the patients (7). However, this strategy is suboptimal for treatment of gliomas, especially the LGGs in which the bulk of evidence show that extent of resection plays an important role in lengthening of progression free survival $(7,21,23,24)$.

After advent of intraoperative brain mapping, surgical resection became feasible for insular gliomas even in those patients who do not have significant preoperative neurological deficits (43). Several studies have proven the positive impact of brain mapping on maximizing the extent of resection in gliomas $(9,24-29)$.

One proposed mechanism for enhancing extent of resection of dominant insular gliomas by intraoperative mapping is brain plasticity and functional reorganization of brain areas involved in important tasks $(6,30)$. This has been previously demonstrated in gliomas of extra-insular locations (31). Based on such reorganization, lack of functional response during subcortical mapping implies that a permanent postoperative deficit is much less likely to occur (8), and makes it possible to continue tumor resection even in anatomically eloquent regions.

To our knowledge, there are few focused reports on the outcome of intraoperative mapping under awake craniotomy in patients with glioma of the dominant insula. Except one study (6), the others have generally reported the safety and efficacy of intraoperative brain mapping disregarding tumor histopathology and location. The major shortcoming of our study was, however, inclusion of LGG and HGG in the same series, despite remarkable difference in the biological behavior of the two groups. This could be overcome in larger studies with stratification of patients according to the biologic features of their tumors.

\section{Conclusion}

Gliomas of the dominant insula represent a challenging subgroup of cerebral gliomas. Their intricate location and proximity to a complex meshwork of functional cortical and subcortical pathways makes their resection challenging.

Based on the results of our series, application of intraoperative brain mapping is an appropriate method in preserving the neurological functions and maximizing tumor resection at the same time. This technique is well tolerated by most, but not all, patients and has no direct long-term complication. Optimal patients for this technique are young patients with LGGs of dominant insula who do not have intense preoperative neurological impairment.

\section{Funding}

None.

\section{Conflicts of Interest}

The authors declare that they have no conflicts of interest.

\section{Authors' Contribution}

All authors of the present study helped in the whole processes from designation to collecting the data and preparing the manuscript.

\section{References}

1. Grieg NH, Ries LG, Yancik R, Rapoport SI. Increasing annual incidence of primary malignant brain tumors in the elderly. Journal of the National Cancer Institute. 1990;17;82(20):1621-4.

2. Farina P, Lombardi G, Bergo E, Roma A, Zagonel V. Treatment of malignant gliomas in elderly patients: a concise overview of the literature. BioMed research international. 2014;22;2014.

3. Della Puppa A, De Pellegrin S, d'Avella E, Gioffrè G, Rossetto M, Gerardi A, Lombardi G, Manara R, Munari M, Saladini M, Scienza R. 5-aminolevulinic acid (5-ALA) fluorescence guided surgery of high-grade gliomas in eloquent areas assisted by functional mapping. Our experience and review of the literature. Acta neurochirurgica. 2013;1;155(6):965-72.

4. Lacroix M, Abi-Said D, Fourney DR, Gokaslan ZL, Shi W, DeMonte F, Lang FF, McCutcheon IE, Hassenbusch SJ, Holland E, Hess K. A multivariate analysis of 416 patients with glioblastoma multiforme: prognosis, extent of resection, and survival. Journal of neurosurgery. 2001;95(2):190-8.

5. Sanai N, Berger MS. Glioma extent of resection and its impact on patient outcome. Neurosurgery. 2008;1;62(4):753-66.

6. Duffau H, Moritz-Gasser S, Gatignol P. Functional outcome after language mapping for insular World Health Organization Grade II gliomas in the dominant hemisphere: experience with 24 patients. Neurosurgical focus. 2009;27(2):E7.

7. Kalani MY, Kalani MA, Gwinn R, Keogh B, Tse VC. Embryological development of the human insula and its implications for the spread and resection of insular gliomas. Neurosurgical focus. 2009;27(2):E2

8. Bertani G, Fava E, Casaceli G, Carrabba G, Casarotti A, Papagno C, Castellano A, Falini A, Gaini SM, Bello L. Intraoperative mapping and monitoring of brain functions for the resection of low-grade gliomas: technical considerations. Neurosurgical focus. 2009;27(4):E4.

9. Bello L, Gallucci M, Fava M, Carrabba G, Giussani C, Acerbi F, Baratta P, Songa V, Conte V, Branca V, Stocchetti N. Intraoperative Subcortical Languagetract Mapping Guides Surgical Removalof Gliomas Involving Speech Areas. Neurosurgery. 2007;1;60(1):67-82.

10. Berger MS. Functional mapping-guided resection of low-grade gliomas. Clinical neurosurgery. 1994;42:437-52.

11. Duffau H, Capelle L, Sichez N, Denvil D, Lopes M, Sichez JP, Bitar A, Fohanno D. Intraoperative mapping of the subcortical language pathways using direct stimulations. Brain. 2002 Jan 1;125(1):199-214

12. Duffau H, Lopes M, Arthuis F, Bitar A, Sichez JP, Van Effenterre R, Capelle 
L. Contribution of intraoperative electrical stimulations in surgery of low grade gliomas: a comparative study between two series without (1985-96) and with (1996-2003) functional mapping in the same institution. Journal of Neurology, Neurosurgery \& Psychiatry. 2005 Jun 1;76(6):845-51.

13. Sanai N, Berger MS. Intraoperative stimulation techniques for functional pathway preservation and glioma resection. Neurosurgical focus. 2010;28(2):E1. 14. Lang FF, Olansen NE, DeMonte F, Gokaslan ZL, Holland EC, Kalhorn C, Sawaya R. Surgical resection of intrinsic insular tumors: complication avoidance. Journal of neurosurgery. 2001;95(4):638-50.

15. Moshel YA, Marcus JD, Parker EC, Kelly PJ. Resection of insular gliomas: the importance of lenticulostriate artery position.

16. Neuloh G, Pechstein U, Schramm J. Motor tract monitoring during insular glioma surgery. Journal of neurosurgery. 2007;106(4):582-92.

17. Simon M, Neuloh G, von Lehe M, Meyer B, Schramm J. Insular gliomas: the case for surgical management: Clinical article. Journal of neurosurgery. 2009;110(4):685-95.

18. Vanaclocha V, Saiz-Sapena N, Garcia-Casasola C. Surgical treatment of insular gliomas. Acta neurochirurgica. 1997;1;139(12):1126-35.

19. Yașargil MG, Von Ammon K, Cavazos E, Doczi T, Reeves JD, Roth P. Tumours of the limbic and paralimbic systems. Acta neurochirurgica. $1992 ; 1 ; 118(1-2): 40-52$

20. Zentner J, Meyer B, Stangl A, Schramm J. Intrinsic tumors of the insula: a prospective surgical study of 30 patients. Journal of neurosurgery. 1996;85(2):263-71.

21. Sanai N, Polley MY, Berger MS. Insular glioma resection: assessment of patient morbidity, survival, and tumor progression: Clinical article. Journal of neurosurgery. 2010;112(1):1-9.

22. Reil JC. Untersuchungen über den Bau des grossen Gehirns im Menschen. Arch Physiol. 1809;9:136-208.

23. McGirt MJ, Chaichana KL, Attenello FJ, Weingart JD, Than K, Burger PC, Olivi A, Brem H, Quinoñes-Hinojosa A. Extent of surgical resection is independently associated with survival in patients with hemispheric infiltrating low-grade gliomas. Neurosurgery. 2008;1;63(4):700-8.

24. Szelényi A, Bello L, Duffau H, Fava E, Feigl GC, Galanda M, Neuloh G, Signorelli F, Sala F. Intraoperative electrical stimulation in awake craniotomy: methodological aspects of current practice. Neurosurgical focus. 2010;28(2):E7. 25. Duffau H. A personal consecutive series of surgically treated 51 cases of insular WHO Grade II glioma: advances and limitations: Clinical article. Journal of neurosurgery. 2009;110(4):696-708.

Duffau H, Capelle L, Denvil D, Sichez N, Gatignol P, Taillandier L, Lopes M, Mitchell MC, Roche S, Muller JC, Bitar A. Usefulness of intraoperative electrical subcortical mapping during surgery for low-grade gliomas located within eloquent brain regions: functional results in a consecutive series of 103 patients. Journal of neurosurgery. 2003;98(4):764-78.

27. Duffau H, Gatignol P, Mandonnet E, Capelle L, Taillandier L. Intraoperative subcortical stimulation mapping of language pathways in a consecutive series of 115 patients with Grade II glioma in the left dominant hemisphere. Journal of neurosurgery. 2008; 109(3):461-471.

28. Eisner W, Burtscher J, Bale R, Sweeney R, Koppelstätter F, Golaszewski S, Kolbitsch C, Twerdy K. Use of neuronavigation and electrophysiology in surgery of subcortically located lesions in the sensorimotor strip. Journal of Neurology, Neurosurgery \& Psychiatry. 2002;1;72(3):378-81.

29. Keles GE, Lundin DA, Lamborn KR, Chang EF, Ojemann G, Berger MS. Intraoperative subcortical stimulation mapping for hemispheric perirolandic gliomas located within or adjacent to the descending motor pathways: evaluation of morbidity and assessment of functional outcome in 294 patients. Journal of neurosurgery. 2004;100(3):369-75.

30. Hayashi Y, Nakada M, Kinoshita M, Hamada JI. Surgical strategies for nonenhancing slow-growing gliomas with special reference to functional reorganization: review with own experience. Neurologia medico-chirurgica. 2013;53(7):438-46.

31. Robles SG, Gatignol P, Lehéricy S, Duffau H. Long-term brain plasticity allowing a multistage surgical approach to World Health Organization Grade II gliomas in eloquent areas. Journal of Neurosurgery. 2008;109(4):615-624. 